\title{
Increased fat in pancreas not associated with risk of pancreatitis post-endoscopic retrograde cholangiopancreatography
}

This article was published in the following Dove Press journal:

Clinical and Experimental Gastroenterology

9 June 2014

Number of times this article has been viewed

\author{
Bhupesh Pokhrel' \\ Eun Kwang Choi' \\ Omer Khalid ${ }^{2}$ \\ Kumar Sandrasegaran ${ }^{3}$ \\ Evan L Fogel' \\ Lee McHenry' \\ Stuart Sherman' \\ James Watkins' \\ Gregory A Cote' \\ Henry A Pitt ${ }^{4}$ \\ Nicholas J Zyromski ${ }^{4}$ \\ Beth Juliar' \\ Glen A Lehman' \\ 'Department of Medicine, Indiana \\ University School of Medicine, \\ Indianapolis, IN, ${ }^{2}$ Department \\ of Gastroenterology, St Louis \\ University School of Medicine, \\ St Louis, MO, ${ }^{3}$ Department of \\ Radiology, ${ }^{4}$ Department of Surgery, \\ Indiana University School of Medicine, \\ Indianapolis, IN, USA
}

Background: A preliminary study has shown increased pancreatic fat in patients with idiopathic pancreatitis and sphincter of Oddi dysfunction. In this study, we aimed to determine if an increased quantity of pancreatic fat is an independent risk factor for pancreatitis post-endoscopic retrograde cholangiopancreatography (ERCP).

Methods: In this case control study, we retrospectively reviewed a local radiological and ERCP database to identify patients who had had abdominal magnetic resonance imaging (MRI) followed by ERCP no more than 60 days later between September 2003 and January 2011. Percentage of fat was determined by recording signal intensity in the in-phase $\left(\mathrm{S}_{\text {in }}\right)$ and out-of-phase $\left(\mathrm{S}_{\text {out }}\right)$ T1-weighted gradient sequences, and calculation of the fat fraction as $\left(\mathrm{S}_{\text {in }}-\mathrm{S}_{\text {out }}\right) /\left(\mathrm{S}_{\text {in }}\right) \times 2$ by an abdominal radiologist blinded to clinical history. Controls matched for age, gender, and other pancreatobiliary disease were selected from a group with no post-ERCP pancreatitis (before fat content of the pancreas was analyzed).

Results: Forty-seven patients were enrolled. Compared with controls, subjects with postERCP pancreatitis were similar in terms of age (41.4 years versus 41.1 years), gender $(21.2 \%$ versus $20.2 \%$ males), pancreatobiliary disease characteristics, and most ERCP techniques. Measurements of pancreatic head, body, and tail fat and body mass index were similar in patients and controls.

Conclusion: Increased pancreatic fat on MRI criteria is not an independent predictor of post-ERCP pancreatitis.

Keywords: magnetic resonance imaging, obesity, pancreatic fat, post-ERCP pancreatitis, sphincter of Oddi dysfunction

\section{Introduction}

Adipose tissue has been characterized as an endocrine organ which secretes proinflammatory adipocytokines, including leptin, tumor necrosis factor-alpha, and interleukin-1 $\beta .{ }^{1}$ Visceral fat plays a key role in obesity-related metabolic dysfunction. Obesity, in turn, is associated with multiple comorbidities, including diabetes, hypertension, and hyperlipidemia. Obesity is also associated with fatty infiltration of organs including the heart, kidneys, and liver. Under conditions of oxidative stress, fat-derived cytokines are released locally and result in an inflammatory process and organ dysfunction. ${ }^{2}$

Increased infiltration of fat in the pancreas has been seen with obesity, senescence, Cushing's syndrome, cystic fibrosis, and lipomatous pseudohypertrophy. ${ }^{2}$ Extreme fatty replacement of the exocrine pancreas may be associated with a decrease in pancreatic function. ${ }^{2}$ Patients who are obese have been documented to have more severe
Correspondence: Glen A Lehman

Physicians - ERCP, $550 \mathrm{~N}$

IN 46202, USA

$\mathrm{Tel}+\mathrm{I} 3179444824$

$\mathrm{Fax}+\mathrm{I} 3179480164$

Email glehman@iupui.edu 
pancreatitis than lean individuals. It has been postulated that a fatty pancreas may be more prone to pancreatitis, similar to the development of nonalcoholic steatohepatitis as a result of nonalcoholic fatty liver disease. ${ }^{3}$

Pancreatitis complicates $1 \%-22 \%$ of endoscopic retrograde cholangiopancreatography (ERCP) procedures. ${ }^{4}$ Obesity is not a clear patient risk factor for post-ERCP pancreatitis. An association between fatty pancreas and postoperative pancreatic fistulae has been reported. ${ }^{5}$ Higher fat content has been observed in the pancreas of patients presenting with pancreatitis secondary to sphincter of Oddi dysfunction compared with patients with sphincter of Oddi dysfunction without pancreatitis. ${ }^{6}$

Magnetic resonance imaging (MRI) can accurately assess tissue fat content by utilizing the slight differences in the MRI signal of hydrogen nuclei in fat and water molecules. Chemical shift imaging has been shown to be accurate in assessment of hepatic fat content compared with liver biopsy ${ }^{7-9}$ and in the assessment of fat in adrenal tumors to distinguish between benign and malignant lesions. ${ }^{10-12}$ Typical MRI images in cases with post-ERCP pancreatitis and controls are shown in Figures 1 and 2, respectively. This study sought a correlation between pancreatic fat content as assessed by MRI and occurrence of pancreatitis post-ERCP. Fat content is a parameter that can be identified before ERCP. If the study showed increased postERCP pancreatitis with increased fat content, it would help with risk stratification and patient consent, and potentially alter management during the procedure, ie, use of pancreatic duct stents or nonsteroidal anti-inflammatory drugs.

\section{Materials and methods}

\section{Patients}

We conducted a case control study of patients who underwent $\mathrm{MRI} /$ magnetic resonance cholangiopancreatography (MRCP) and ERCP at the Indiana University Medical Center. Subjects included patients who had an abdominal MRI/MRCP followed

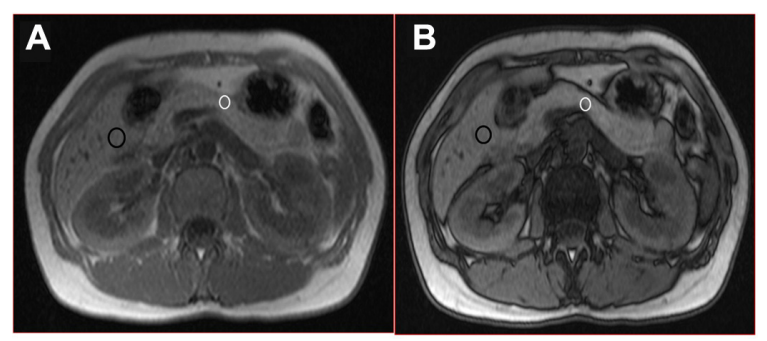

Figure I TI-weighted in-phase (A) and out-of-phase (B) axial images in 44-year old female who did not have post-ERCP pancreatitis.

Notes: The region-of-interest (ROI) over the pancreas (white circle) show no drop off in signal and indicating a I\% fat content of the body of the gland. The ROI over the liver (dark circle) also show only $2 \%$ fat content.

Abbreviation: ERCP, endoscopic retrograde cholangiopancreatography.

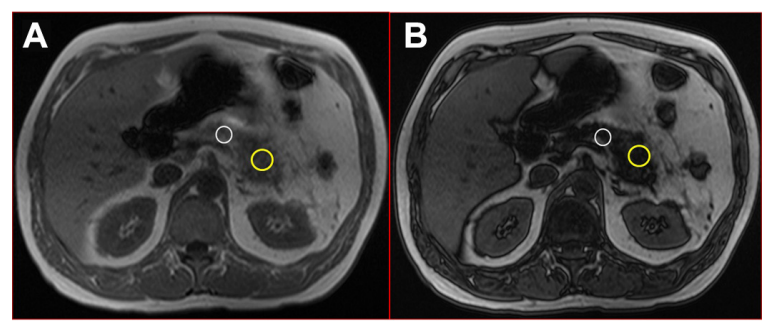

Figure 2 TI-weighted in-phase (A) and out-of-phase (B) axial images in 52-year old male who subsequently developed post-ERCP pancreatitis.

Notes: The ROls over the body (white circle) and tail (yellow circles) of pancreas show significant darkening (dark off) of signal on image B, consistent with a pancreatic body and tail fat content of $29 \%$ and $33 \%$, respectively. However, the findings of Figures $I$ and 2 were not uniformly seen in patients who had or did not have post-ERCP pancreatitis.

Abbreviation: $\mathrm{ERCP}$, endoscopic retrograde cholangiopancreatography.

by an ERCP no more than 60 days later from September 2003 to January 2011. Permission to review a database maintained to monitor the care of these patients was granted by the institutional review board at Clarian Health Partners/Indiana University, Purdue University, Indianapolis, IN, USA. Case subjects were patients who developed post-ERCP pancreatitis. Control subjects included patients who underwent ERCP without developing pancreatitis who were matched for age, gender, and indications for ERCP. Standard definitions of postERCP pancreatitis and severity were used. ${ }^{13}$ All ERCPs were done by six faculty members and eight advance endoscopy fellows in training. No one person did more than ten cases.

\section{MRI analysis}

All MRI images were reviewed, with emphasis on fat content of the head, body, and tail of the pancreas, by an abdominal radiologist (SK) with 13 years of experience in interpreting abdominal MRI. The percentage fat was determined by recording the signal intensity in the in-phase $\left(\mathrm{S}_{\text {in }}\right)$ and out-of-phase $\left(\mathrm{S}_{\text {out }}\right)$ T1-weighted gradient echo sequences and subsequently calculating the fat fraction as $\left(\mathrm{S}_{\text {in }}-\mathrm{S}_{\text {out }}\right) /\left(\mathrm{S}_{\text {in }} \times 2\right)$.

\section{Inclusion and exclusion criteria}

All patients who had an MRCP followed by ERCP within 60 days for suspected sphincter of Oddi dysfunction, pancreas divisum, or evaluation of acute recurrent pancreatitis were selected. Patients with pancreatic cancer, pseudocysts, chronic pancreatitis (diagnosed before ERCP such as by computed tomography scan) or biliary tract disease were excluded. Patients who had intervening pancreatic surgery between MRI and ERCP were also excluded.

\section{Statistical analysis}

The statistical analysis was performed using the Statistical Package for Social Sciences version 17.0 (SPSS Inc, 
Chicago, IL, USA).The chi-square test was used to assess for differences in baseline characteristics between the two groups. If the expected count of each cell was less than five, Fisher's exact test was used to evaluate the difference between groups. The Student's $t$-test was used to compare the mean pancreatic fat content between the groups. Stepwise logistic regression analysis was performed to find the best predictor(s) of post-ERCP pancreatitis. At each step, the likelihood ratio test was used to determine if the parameter was to be entered into the model. The fat content of the head, body, and tail of the pancreas, as well as age, gender, and body mass index were evaluated as parameters. Correlation analysis was used to investigate the relationship between body mass index and pancreatic fat content. A $P$ value $<0.05$ was considered to be statistically significant.

\section{Results}

We identified 47 patients who developed post-ERCP pancreatitis and had an MRI within 60 days of their ERCP. A further 74 subjects underwent MRI followed by ERCP within 60 days and did not develop post-ERCP pancreatitis. Cases of post-ERCP pancreatitis and controls did not differ with respect to age (41.4 years versus 41.1 years, $P=0.89)$ or gender $(21.2 \%$ versus $20.2 \%$ males, $P=0.8$ ). Table 1 summarizes the patient characteristics and demographics. There were no statistically significant differences between the two groups for baseline parameters, as shown in Table 1. Both groups were similar with respect to indications for ERCP, extent of pancreatic duct filling, manometry measurements, pancreatic duct stent placement, history of post-ERCP pancreatitis, history of recurrent acute pancreatitis, and evidence of chronic pancreatitis (Table 2), except that the pancreatitis group underwent more biliary and pancreatic sphincterotomies.

Table 3 summarizes the fat content between the two groups. Figures 3 and 4 show the distribution of fat content in cases of post-ERCP pancreatitis and controls. The mean fat

Table I Baseline patient characteristics

\begin{tabular}{|c|c|c|c|}
\hline $\begin{array}{l}\text { Patient } \\
\text { characteristics }\end{array}$ & $\begin{array}{l}\text { Cases } \\
(n=47)\end{array}$ & $\begin{array}{l}\text { Controls } \\
(n=74)\end{array}$ & P-values \\
\hline Age (mean, SD) & $41.4 \pm 15.8$ & $4 I . I \pm 2 I .4$ & 0.89 \\
\hline Gender (females, \%) & 37 (78.7\%) & $59(79.7 \%)$ & 0.81 \\
\hline Weight in kg (SD) & $71.07 \pm 20.1$ & $75.6 \pm 19.9$ & 0.08 \\
\hline Mean BMI (SD) & $25.38 \pm 4.9$ & $27.96 \pm 7.7$ & 0.13 \\
\hline Hypertension & $21.20 \%$ & $21.60 \%$ & I \\
\hline Diabetes mellitus & $8.50 \%$ & $14.80 \%$ & 0.56 \\
\hline Dyslipidemia & $14.80 \%$ & $16.20 \%$ & 0.79 \\
\hline
\end{tabular}

Abbreviations: BMI, body mass index; SD, standard deviation.
Table 2 Cases and controls according to their diagnosis, ERCP findings, history of recurrent acute pancreatitis, history of post-ERCP pancreatitis, and evidence of chronic pancreatitis

\begin{tabular}{|c|c|c|c|}
\hline & $\begin{array}{l}\text { PEP cases } \\
(n=47)\end{array}$ & $\begin{array}{l}\text { Controls } \\
(n=74)\end{array}$ & $P$-values \\
\hline \multicolumn{4}{|l|}{ Final diagnosis* } \\
\hline $\begin{array}{l}\text { Sphincter of Oddi } \\
\text { dysfunction** }\end{array}$ & $35(74.4 \%)$ & $65(87.8 \%)$ & 0.08 \\
\hline Pancreatic divisum & $7(14.9 \%)$ & $8(10.8 \%)$ & 0.57 \\
\hline Pancreatic duct stricture & $10(21.3 \%)$ & $9(12.2 \%)$ & 0.2 \\
\hline Idiopathic pancreatitis & $2(4.3 \%)$ & $3(4.1 \%)$ & I \\
\hline IPMN & I (I.4\%) & I (2.I\%) & I \\
\hline \multicolumn{4}{|l|}{ Pancreatic duct filling } \\
\hline Head, body, and tail & $32(68 \%)$ & $42(56.7 \%)$ & 0.25 \\
\hline Head and body & II (23.4\%) & $23(31 \%)$ & $0.4 \mathrm{I}$ \\
\hline Head only & 0 & $3(4 \%)$ & 0.28 \\
\hline None & $4(8.5 \%)$ & $6(8.1 \%)$ & I \\
\hline \multicolumn{4}{|l|}{ Manometry measurements } \\
\hline Biliary and pancreatic & $26(55.3 \%)$ & $37(50 \%)$ & 0.58 \\
\hline Biliary only & $5(10.6 \%)$ & 14 (18.9\%) & 0.3 \\
\hline Pancreatic only & $6(12.8 \%)$ & $12(16.2 \%)$ & 0.79 \\
\hline None & $10(21.3 \%)$ & II (I4.9\%) & 0.46 \\
\hline \multicolumn{4}{|l|}{ Sphincterotomy } \\
\hline Biliary and pancreatic & 29 (61.7\%) & $46(62.1 \%)$ & I \\
\hline Pancreatic only & $13(27.6 \%)$ & $8(10.8 \%)$ & 0.02 \\
\hline Biliary only & $2(4.2 \%)$ & $12(16.2 \%)$ & 0.04 \\
\hline None & $3(6.3 \%)$ & $8(10.8 \%)$ & I \\
\hline $\begin{array}{l}\text { Pancreatic duct stent } \\
\text { placement }\end{array}$ & 43 (9l.4\%) & $63(85.1 \%)$ & 0.24 \\
\hline $\begin{array}{l}\text { History of recurrent acute } \\
\text { pancreatitis }\end{array}$ & $24(51 \%)$ & $36(48.6 \%)$ & 0.85 \\
\hline History of PEP & $4(8.5 \%)$ & $5(6.7 \%)$ & 0.73 \\
\hline $\begin{array}{l}\text { Evidence of chronic } \\
\text { pancreatitis }\end{array}$ & $13(27.6 \%)$ & $18(24.3 \%)$ & 0.83 \\
\hline
\end{tabular}

Notes: *Some patients have more than one diagnosis; **includes patients with basal sphincter of Oddi pressures $\geq 40 \mathrm{mmHg}$ in either the biliary or pancreatic sphincter segment.

Abbreviations: IPMN, intraductal papillary mucinous neoplasm; PEP, postendoscopic retrograde cholangiopancreatography pancreatisis; ERCP, endoscopic retrograde cholangiopancreatography.

content in the head of the pancreas (4.9\% versus $5.5 \%)$ was numerically lower in patients with post-ERCP pancreatitis in comparison with the control population. The mean fat content in the body $(6.2 \%$ versus $5.4 \%)$ and tail $(5.3 \%$

Table 3 Pancreatic fat content in head, body, and tail in patients with post-ERCP pancreatitis versus controls

\begin{tabular}{lllll}
\hline Patient groups & $\mathbf{n}$ & Mean & SD & P-values \\
\hline Head fat & & & & \\
$\quad$ Controls & 74 & $5.50 \%$ & 7.7 & 0.63 \\
$\quad$ PEP cases & 47 & $4.90 \%$ & 6.7 & \\
Body fat & & & & \\
$\quad$ Controls & 74 & $5.40 \%$ & 7.7 & 0.59 \\
$\quad$ PEP cases & 47 & $6.20 \%$ & 8.4 & \\
Tail fat & & & & \\
$\quad$ Controls & 74 & $4.90 \%$ & 6.7 & 0.81 \\
$\quad$ PEP cases & 47 & $5.30 \%$ & 7.6 & \\
\hline
\end{tabular}

Abbreviations: PEP, post-endoscopic retrograde cholangiopancreatography pancreatisis; SD, standard deviation; ERCP, endoscopic retrograde cholangiopancreatography. 


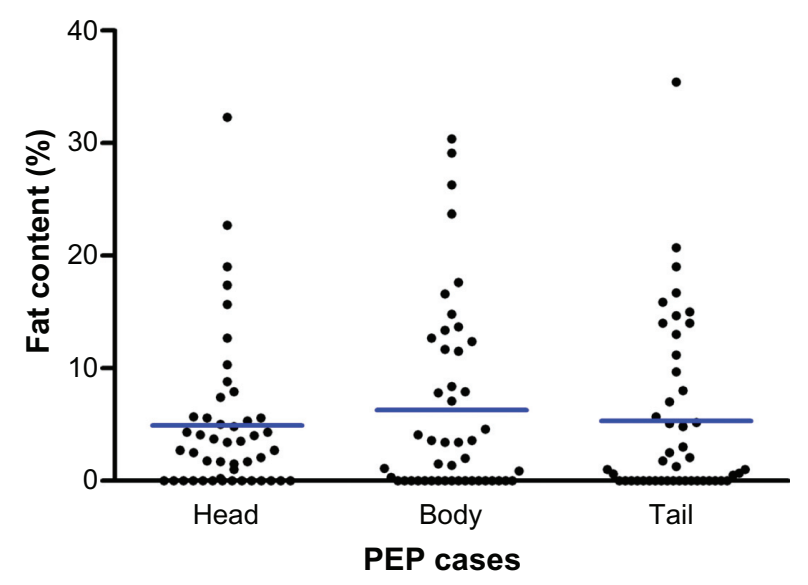

Figure 3 Fat content of head, body, and tail of pancreas in patients with PEP. Abbreviation: PEP, post-endoscopic retrograde cholangiopan-creatography pancreatisis.

versus $4.9 \%$ ) of the pancreas was numerically higher in patients with post-ERCP pancreatitis. None of the differences were statistically significant.

Of the 47 patients with post-ERCP pancreatitis, the pancreatitis was mild in severity in 41 , moderate in one, and severe in five patients. The mean fat content of the head $(5.2 \%)$, body $(4.8 \%)$, and tail $(1.1 \%)$ in moderate to severe cases was not significantly different from controls nor from patients with mild pancreatitis (head $4.9 \%$, body $6.5 \%$, tail $5.9 \%$ respectively, Table 4 ). Further, no statistically significant correlation was found between mean body mass index and fat content of the pancreas in our patient population, as shown in Table 5.

\section{Discussion}

Pancreatitis remains the most frequent complication of ERCP. In high-risk patients, such as those with suspected sphincter of Oddi disturbance, post-ERCP pancreatitis

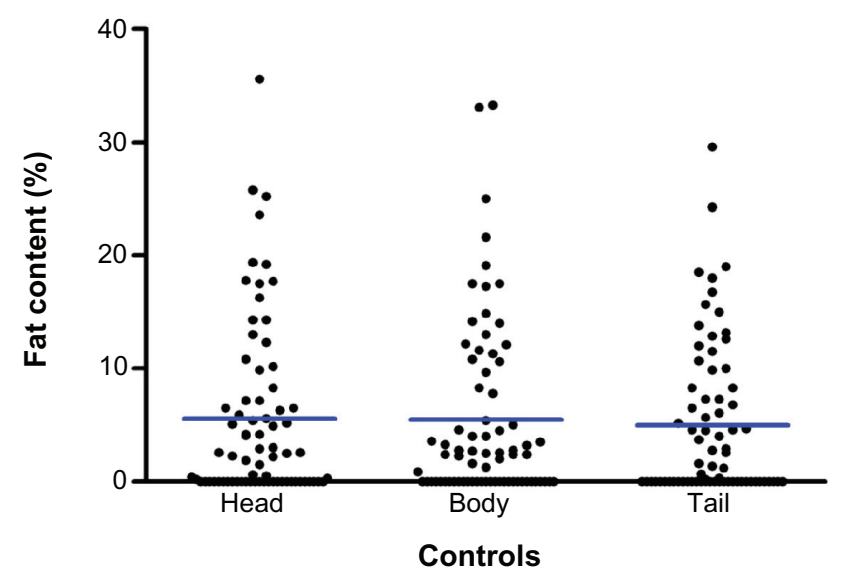

Figure 4 Fat content of head, body, and tail of pancreas in controls.
Table 4 Relationship between severity of pancreatitis post-endoscopic retrograde cholangiopancreatography and pancreatic fat content

\begin{tabular}{lllll}
\hline & $\begin{array}{l}\text { Controls } \\
(\mathbf{n = 7 4 )}\end{array}$ & $\begin{array}{l}\text { Mild } \\
\text { pancreatitis } \\
(\mathbf{n}=\mathbf{4 I})\end{array}$ & $\begin{array}{l}\text { Moderate } \\
\text { to severe } \\
\text { pancreatitis } \\
(\mathbf{n}=\mathbf{6})\end{array}$ & P-values \\
\hline Head fat & $5.60 \%$ & $4.90 \%$ & $5.20 \%$ & 0.88 \\
Body fat & $5.50 \%$ & $6.50 \%$ & $4.80 \%$ & 0.77 \\
Tail fat & $5.00 \%$ & $5.90 \%$ & $1.10 \%$ & 0.29 \\
\hline
\end{tabular}

rates are as high as $20 \%$. Numerous studies have addressed this topic. The first challenge in clinical practice is to identify patients at risk of developing post-ERCP pancreatitis, in order to establish whether the risk/benefit ratio is favorable and whether noninvasive diagnostic procedures and/or other therapeutic procedures might be adequate or more appropriate.

There are both patient-related and procedure-related risk factors for the development of post-ERCP pancreatitis. In a review by Freeman et al, young age, female gender, suspected sphincter of Oddi dysfunction, history of prior post-ERCP pancreatitis, recurrent pancreatitis, and absence of chronic pancreatitis were identified as independent patient-related risk factors. Biliary orifice balloon dilatation, difficult cannulation, pancreatic sphincterotomy, and number of pancreas duct injections were significant procedure-related risks for pancreatitis. The degrees of pancreatic duct filling at ERCP and trainee involvement are independent risk factors as well. Patients who are obese have been documented to have more severe gallstone-related and alcohol-related pancreatitis than lean individuals. ${ }^{14-16}$

The two main techniques used to assess fat content are proton $\left({ }^{1} \mathrm{H}\right)$ magnetic resonance spectroscopy ${ }^{17-19}$ and chemical shift imaging. ${ }^{20-22}$ Both of these techniques utilize slight differences in the MRI signal of hydrogen nuclei in fat and water molecules. In long-chain aliphatic fat molecules, the hydrogen nuclei (protons) are surrounded by a cloud of electrons. In contrast, in water molecules, the hydrogen nuclei are relatively devoid of electron cover, because the electrons are attracted towards the oxygen nucleus. As a result, fat protons experience a slightly lower local magnetic field, and vibrate (precess) at a lower frequency than water protons. This difference in precessional frequency may be used in chemical shift imaging to acquire images where the signals from water and fat protons are additive (in-phase) and where the signals from the two nuclear species are subtractive (out-ofphase). On out-of-phase images, the signal in tissue where 
Table 5 Pearson correlation between mean body mass index and fat content in head, body, and tail

\begin{tabular}{llll}
\hline & Head fat & Body fat & Tail fat \\
\hline BMI $\left(\mathrm{kg} / \mathrm{m}^{2}\right)$ & & & \\
Correlation & & & \\
coefficient & & & \\
$\quad$ PEP cases & $0.17(P=0.39)$ & $0.31(P=0.12)$ & $0.16(P=0.43)$ \\
$\quad$ Controls & $0.13(P=0.44)$ & $0.22(P=0.16)$ & $0.09(P=0.60)$ \\
\hline
\end{tabular}

Abbreviations: $\mathrm{BMI}$, body mass index; $\mathrm{PEP}$, post-endoscopic retrograde cholangiopancreatography pancreatisis.

there is a substantial fat content is reduced. The fat fraction of a volume of tissue may be calculated by the formula: $\left(\mathrm{S}_{\text {in }}-\mathrm{S}_{\text {out }}\right) /\left(\mathrm{S}_{\text {in }} \times 2\right)$, where $\mathrm{S}_{\text {in }}$ is the signal intensity of the volume of tissue on in-phase images, and $\mathrm{S}_{\text {out }}$ is the signal on out-of-phase images.

Fatty pancreas has been the focus of attention over the past few years as a risk factor for developing pancreatitis. It has been implicated in the surgical literature as a risk factor for development of postoperative pancreatic fistulae after pancreatoduodenectomy. ${ }^{5} \mathrm{~A}$ recent article by Zyromski et al compared pancreatic tissue from leptin-deficient obese mice and lean controls..$^{22}$ They noted the obese mice to have a higher fat content in their pancreatic tissue and increased levels of cytokines, suggesting that a fatty pancreas is more prone to pancreatitis. Also, patients with idiopathic pancreatitis and sphincter of Oddi dysfunction are more likely to have a fatty pancreas than controls. ${ }^{6}$

Our study addressed the issue of pancreatic fat content as evaluated by MRI and any correlation between fat content and post-ERCP pancreatitis. Despite other studies showing a correlation between increased pancreatic fat content and pancreatic disease, such as fistulae, idiopathic pancreatitis, and cystic fibrosis, no statistically significant correlation was found in this study. Our study evaluated patients at high risk for post-ERCP pancreatitis, but studies of lower-risk patients with post-ERCP pancreatitis, such as those with common bile duct stones, would be of interest.

There are several limitations in our study. First, it had a case control design. Although we compared patients with post-ERCP pancreatitis and alleged post-ERCP pancreatitis risk-matched controls, because the etiology of post-ERCP pancreatitis is not fully understood and multifactorial, we could not control all possible factors. Second, the number of patients with post-ERCP pancreatitis enrolled was small and originated from one center. Although there was no obvious trend showing a correlation between post-ERCP pancreatitis and pancreatic fat content in this study, more data from a multicenter study might possibly show different results.
Previous studies have demonstrated a correlation between pancreatic fat content and obesity. Our study failed to show such an association. Given that post-ERCP pancreatitis is relatively uncommon, the small study population might also be a factor. Additional ERCP studies which appear warranted include the following:

- A prospective study addressing the same issues as our retrospective study (given that some prospective studies have higher post-ERCP pancreatitis rates than retrospective studies)

- A study attempting to correlate pre-ERCP weight loss and post-ERCP pancreatitis frequency, particularly in morbidly obese patients

- A larger study with greater statistical power to address further the minor trends shown in Table 3

- A larger study with greater statistical power to address the frequency of moderate/severe post-ERCP pancreatitis.

In summary, our analysis of patients who developed post-ERCP pancreatitis suggests that increased pancreatic fat content does not increase the risk of post-procedure pancreatitis. Further studies are needed, as outlined above.

\section{Acknowledgments}

The authors are grateful to Lee McHenry, James L Watkins, Stuart Sherman, Evan L Fogel, and Nicholas J Zyromski for editing of the manuscript, to Gregory A Coté for conception, design, and editing, and to Beth Juliar for statistical analysis.

\section{Disclosure}

The authors report no conflicts of interest in this work.

\section{References}

1. Greenberg AS, Obin MS. Obesity and the role of adipose tissue in inflammation and metabolism. Am J Clin Nutr. 2006;83:461S-465S.

2. Mathur A, Marine M, Lu D, et al. Nonalcoholic fatty pancreas disease. HPB. 2007;9:312-318

3. Pitt HA. Hepato-pancreato-biliary fat: the good, the bad and the ugly. HPB. 2007;9:92-97.

4. Saad AM, Fogel EL, McHenry L, et al. Pancreatic duct stent placement prevents post-ERCP pancreatitis in patients with suspected sphincter of Oddi dysfunction but normal manometry results. Gastrointest Endosc. 2008;67:255-261.

5. Mathur A, Pitt HA, Marine M, et al. Fatty pancreas: a factor in postoperative pancreatic fistula. Ann Surg. 2007;246:1058-1064.

6. Mathur A, Sandrasegaran K, Zyromski NJ, et al. Fatty pancreas - a risk factor for the development of SOD pancreatitis. Gastrointest Endosc. 2008;67:AB328.

7. d'Assignies G, Ruel M, Khiat A, et al. Noninvasive quantitation of human liver steatosis using magnetic resonance and bioassay methods. Eur Radiol. 2009;19:2033-2040.

8. Bahl M, Qayyum A, Westphalen AC, et al. Liver steatosis: investigation of opposed-phase T1-weighted liver MR signal intensity loss and visceral fat measurement as biomarkers. Radiology. 2008;249:160-166. 
9. Qayyum A, Chen DM, Breiman RS, et al. Evaluation of diffuse liver steatosis by ultrasound, computed tomography, and magnetic resonance imaging: which modality is best? Clin Imaging. 2009;33:110-115.

10. Outwater EK, Blasbalg R, Siegelman ES, Vala M. Detection of lipid in abdominal tissues with opposed-phase gradient-echo images at $1.5 \mathrm{~T}$ : techniques and diagnostic importance. Radiographics. 1998;18: 1465-1480.

11. Bilbey JH, McLoughlin RF, Kurkjian PS, et al. MR imaging of adrenal masses: value of chemical-shift imaging for distinguishing adenomas from other tumors. AJR Am J Roentgenol. 1995;164:637-642.

12. Korobkin M, Giordano TJ, Brodeur FJ, et al. Adrenal adenomas: relationship between histologic lipid and CT and MR findings. Radiology. 1996;200:743-747.

13. Cotton PB, Lehman G, Vennes J, et al. Endoscopic sphincterotomy complications and their management: an attempt at consensus. Gastrointest Endosc. 1991;37:383-393.

14. Freeman ML, DiSario JA, Nelson DB, et al. Risk factors for ERCP pancreatitis: a prospective, multicenter study. Gastrointest Endosc. 2001;54:425-434.

15. Masci E, Mariani A, Curioni S, Testoni PA. Risk factors for pancreatitis following endoscopic retrograde cholangiopancreatography: a meta-analysis. Endoscopy. 2003;35:830-834.
16. Abdel Aziz AM, Lehman GA. Pancreatitis after endoscopic retrograde cholangio-pancreatography. World J Gastroenterol. 2007;13: 2655-2668.

17. Cowin GJ, Jonsson JR, Bauer JD, et al. Magnetic resonance imaging and spectroscopy for monitoring liver steatosis. JMagn Reson Imaging. 2008;28:937-945.

18. Irwan R, Edens MA, Sijens PE. Assessment of the variations in fat content in normal liver using a fast MR imaging method in comparison with results obtained by spectroscopic imaging. Eur Radiol. 2008;18: 806-813.

19. Mehta SR, Thomas EL, Bell JD, Johnston DG, Taylor-Robinson SD. Non-invasive means of measuring hepatic fat content. World $J$ Gastroenterol. 2008;14:3476-3483.

20. Kalra N, Duseja A, Das A, Kalra N, Duseja A, Das A. Chemical shift magnetic resonance imaging is helpful in detecting hepatic steatosis but not fibrosisin patients with nonalcoholic fatty liver disease (NAFLD). Ann Hepatol. 2009;8:21-25.

21. Mazhar SM, Shiehmorteza M, Sirlin CB. Noninvasive assessment of hepatic steatosis. Clin Gastroenterol Hepatol. 2009;7:135-140.

22. Zyromski NJ, Mathur A, Pitt HA, et al. A murine model of obesity implicates the adipokine milieu in the pathogenesis of severe acute pancreatitis. Am J Physiol. Gastrointest Liver Physiol. 2008;295: G552-G558.
Clinical and Experimental Gastroenterology

\section{Publish your work in this journal}

Clinical and Experimental Gastroenterology is an international, peerreviewed, open access journal, publishing all aspects of gastroenterology in the clinic and laboratory, including: Pathology, pathophysiology of gastrointestinal disease; Investigation and treatment of gastointestinal disease; Pharmacology of drugs used in the alimentary tract;

\section{Dovepress}

Immunology/genetics/genomics related to gastrointestinal disease. This journal is indexed on CAS. The manuscript management system is completely online and includes a very quick and fair peer-review system. Visit http://www.dovepress.com/testimonials.php to read real quotes from published authors.

Submit your manuscript here: http://www.dovepress.com/clinical-and-experimental-gastroenterology-journal 